\title{
VIRTUE ETHICS AND LEGAL ETHICS
}

\author{
Tim Dare*
}

Tim Dare rejects the widely held view that lawyers should bring their own moral beliefs to bear in their professional lives. He rejects the current trend to favour character based accounts of ethics (virtue ethics) over rule or principle based models of ethics. Rule based approaches are necessary to professional ethics because of the important public role that lawyers play in implementing the agreements reached between competing interest groups in society that are enshrined in law. Moreover, he argues, for the lawyer client relationship to work it is imperative that the client is aware of the moral code that the lawyer will bring to their work. This is only possible where the moral code is public and uniform, not personal and opaque.

\section{INTRODUCTION}

Much recent discussion of legal ethics has focused upon the idea that the ethical obligations and permissions to which lawyers are subject are "role-differentiated". According to the role-differentiation thesis, the obligations and permissions to which we are subject vary as we move between roles. Those which attach to certain roles may conflict with and override "ordinary" or "general" morality. When applied to law, the suggestion is that lawyers may be allowed or required to do things qua lawyers which would be wrong if done by non-lawyers or by lawyers "at home". This idea is central to the "standard conception of the lawyer's role". Though there are various strands to the now widespread criticism of the standard conception, it will do to portray them as sharing an ambition to weaken the distinction the conception seeks to draw between professional and general morality. Gerald Postema, for instance, argues that by divorcing lawyers from "the resources of a broader moral experience" the standard conception makes it impossible for lawyers to preserve their sense of moral responsibility. Hence Postema argues for a new conception of the lawyer's role which "achieves a fully integrated moral personality" and "allows the lawyer to bring his full moral sensibilities to play in his professional role".

BA, LLB (Hons), M Jur, PhD (Alberta); Lecturer in Philosophy, University of Auckland.

1 G Postema “Moral Responsibility in Professional Ethics" (1980) 55 New York University Law Review 63,64 . 
This debate within legal ethics connects directly with one of the most striking features of contemporary moral philosophy - the rediscovery of Aristotle. At the heart of this renaissance is the idea that moral deliberation and justification cannot proceed deductively through the application of general principles to particular cases. Aristotle supposes that the phenomena with which ethical inquiry is concerned is marked by mutability, indeterminacy and particularity, such that they can never be unproblematically subsumed under general principles of right action. His view of the limitations of general principles of right action led him to stress the importance of "practical judgment" (phronesis), a practical reasoning skill which is neither a matter of simply applying general principles to particular cases nor of mere intuition. Phronesis is a complex faculty in which general principles and the particularities of the case both play a role. ${ }^{2}$ The phronimos relies upon his or her judgment to identify the right thing to do in light both of principles and the exigencies of the particular case. This emphasis upon judgment brings the character of the practical reasoner to centre-stage. We cannot look to general principles to settle what is the right thing to do, hence we must look to the character - or virtues - of those doing the judging.

Although the Aristotelian model once dominated normative theory, including legal theory, it fell into disfavour around the time of the scientific revolution. Recently there has been a dramatic return to Aristotle. Though it is difficult to characterise virtue theory so as to capture all that has been gathered under that rubric, it will do for our purposes to understand a virtue theory as one which holds that judgments about the character of persons, independently of assessments of the rightness or the value of the consequences of their actions, is what is most fundamental in moral evaluation. Bluntly, virtue theories are character-based in so far as they eschew principle or rule based moral reasoning and place emphasis instead upon the judgment of moral agents. A flavour of the new wave of virtue theory, understood in this rather broad fashion, may be gained from John McDowell, who maintains that morality is "uncodifiable". He writes that "one knows what to do (if one does) not by applying universal principles but by being a certain sort of person: one who sees situations in a certain way". ${ }^{3}$ In a similar vein Martha Nussbaum states that "[t]he conception of ethical theory on which I rely is, roughly, an Aristotelian one", ${ }^{4}$ while

2 "Practical wisdom is not concerned with universals only; it must also recognise particulars, for it is practical and practice concerns particulars". Aristotle Nicomachean Ethics 1141b14-16 (Penguin, Harmondsworth, 1953).

3 J McDowell "Virtue and Reason" in Anti-Theory in Ethics and Moral Conservatism S G Clarke and E Simpson (eds) (State University of New York Press, Albany, 1989) 87-109, 105.

4 M Nussbaum The Fragility of Goodness: Luck and Ethics in Greek Tragedy and Philosophy (Cambridge University Press, New York, 1986) 10. 
arguing for the priority of perception over rules and claiming that "to confine ourselves to the universal is a recipe for obtuseness".

Gerald Postema and other significant contributors to the legal ethics debate belong squarely within this Aristotelian renaissance. Postema's new conception of the lawyer's role is essentially Aristotelian. It rejects the idea that lawyers might look to appropriate rules of principles of right action for moral guidance, in favour of a view based on the claim that "[i]n professional contexts there is much need for practical judgment in this Aristotelian sense." ${ }^{6}$ Similarly, Anthony Kronman's recent book, The Lost Lawyer, ${ }^{7}$ charts and attempts to remedy the costs of the demise of a once dominant professional ideal which portrayed the good lawyer as Aristotle's phronemos. This professional ideal served as a model for lawyers for the better part of two centuries. With its demise lawyers have come to regard law as an essentially technical discipline, requiring no particular character or virtue on the part of its leading practitioners, judges, and teachers. Kronman aims to revise and revive the Aristotelian ideal, to show that the lawyer must "have certain traits of character to attain a high level of achievement in the practice of law. In these traits we may hope to find a foundation for the belief that to be a lawyer is to be a person of a particular kind, a person one may reasonably take pride in being, rather than an expert with no particular character at all". ${ }^{8}$ According to Kronman, then, the good lawyer is just a virtuous person. ${ }^{9}$

It seems to me however that this turn to virtue or character based approaches in legal ethics is mistaken. I will argue that the approach has only a limited contribution to make to a proper understanding of lawyer's ethical responsibilities and that the standard conception is basically correct. Indeed, I will argue that as virtue or character based approaches are currently defended within the legal ethics debate, taking them seriously would make lawyers less rather than more likely to fulfil their professional ethical obligations.

5 M Nussbaum "Richly Aware and Finely Responsible: Literature and the Moral Imagination" in Anti-Theory in Ethics and Moral Conservatism, above n 3, 122-134, 126.

6 Above n 1, 68

7 A Kronman The Lost Lawyer (Belknap Press, Cambridge, Mass, 1993).

8 Above $n$ 7, 208.

9 I discuss an intriguing branch of the attempt to ground legal ethics in virtue ethics in T Dare "The Secret Courts of Men's Hearts: Legal Ethics and Harper Lee's To Kill a Mockingbird", forthcoming in K Economides (ed) Ethical Challenges to Legal Education and Conduct (Hart Publishing, Oxford, 1997). The paper addresses a significant literature which argues that Atticus Finch, the hero of Harper Lee's novel, should be adopted as an ethical role model by lawyers. In essence, Atticus is presented as the phronemos. 


\section{CHARACTER-BASED ETHICS AND THE NATURE OF MORAL REASONING}

I begin by considering an extreme rejection of rule and principle based moral reasoning. According to Hubert and Stuart Dreyfus, not only do "moral experts" not use principles or rules in their reasoning, they cannot do so - either in the process of moral deliberation or in giving an account to others of why and how they have made particular judgments. ${ }^{10}$ I will claim that this cannot be an adequate account of ethical expertise. Ethics, I will suggest, is an ineluctably public endeavour. The possibility that one's ethical choices could be justified and explained in terms of reasons which are at least coherent, if not convincing, is not an optional matter. It is a constitutive element of ethical practice. The doubts here go to the adequacy of certain kinds of particularist virtue theories as ethical theories.

Hubert and Stuart Dreyfus set out to give an account of the phenomenology of moral reasoning. They target what they call the intellectualist tradition which they think has emphasised the role of deliberation and appeal to rule and principle in moral reasoning to the neglect of the possibility "that our moral consciousness expresses itself chiefly in everyday ethical comportment which consists in unreflective, egoless responses to the current interpersonal situation." ${ }^{11}$ They aim to remedy this neglect by defending an account of "expertise" in general which they then apply to ethical expertise. It seems, they write: ${ }^{12}$

... that beginners make judgments using strict rules and features, but that with talent and a great deal of involved experience the beginner develops into an expert who sees intuitively what to do without applying rules and making judgments at all. The intellectualist tradition has given an accurate description of the beginner and of the expert facing an unfamiliar situation, but normally an expert does not deliberate. She does not reason. She does not even act deliberately. She simply spontaneously does what has normally worked and, naturally, it normally works.

They use drivers and chess players as examples. So we are said to teach people to drive by breaking driving down into a number features which can be recognised even by raw beginners: the beginner driver is taught the rule "when the speedo points to $15 \mathrm{kmph}$, change out of first gear". Advanced beginners - the next stage - begin to note or are taught

10 H L Dreyfus and S E Dreyfus "What is Morality? A Phenomenological Account of the Development of Ethical Expertise" in Universalism and Communitarianism D Rasmussen (ed), (MIT Press, Cambridge, Mass, 1990) 237-264.

11 Above n 10, 239.

12 Above n 10, 243. 
additional components of the situation in which the skill is exercised, and they use these situational aspects to develop maxims of action: so the advanced - beginner driver learns to use engine noise as well as speed to decide when to change gear. At the next level competence - the practitioner chooses plans by which they select, on grounds of relevance to the plan, some of the features and aspects they have learned. Here we find detached planning, conscious assessment of elements salient with respect to the plan, and analytical rule-guided choice of action. The use of plans of action introduces an emotional component because choosing plans in the absence of rules is stressful. Next, moving from competence to proficiency: ${ }^{13}$

[h]aving experienced many emotional laden situations, chosen plans in each, and having obtained vivid, emotional demonstrations of the adequacy or inadequacy of the plan, the performer involved in the world of skill "notices", or "is struck by" a certain plan, goal or perspective. No longer is the spell of involvement broken by detached conscious planning.

They continue and claim "The proficient performer, immersed in the world of skilful activity sees what has to be done but must [still] decide how to do it. ${ }^{.14}$ With sufficient experience with a wide enough variety of situations the proficient performer decomposes these situations into subclasses, each of which shares the same action or tactic, allowing an immediate intuitive response to each situation. So: ${ }^{15}$

The expert driver, generally without any awareness, not only knows by feel and familiarity when an action such as slowing down is required; she knows how to perform the action without calculating and comparing alternatives. She shifts gears when appropriate with no awareness of her acts. On the off ramp her foot simply lifts off the accelerator. What must be done, simply is done.

If the skill model is correct, and if everyday ethical comportment is a form of expertise, the Dreyfus' conclude: ${ }^{16}$

we should expect ethical expertise to exhibit a developmental structure similar to that just described. On analogy with chess and driving it would seem that the budding ethical expert would learn at least some of the ethics of her community by following strict rules, would then go on to apply contextualised maxims, and, in the highest stage, would leave rules and principles behind and develop more and more refined spontaneous ethical responses.

13 Above n 10, 242.

14 Above n 10, 243.

15 Above n 10, 243.

16 Above n 10, 244. 
Perhaps enough has already been said to show that Dreyfus and Dreyfus think deliberation and reflection have only a very small role in moral reasoning, and then only during rehearsals for the real show or activity. It will be worth picking this theme out a little more clearly, however, since it is what I am particularly interested in. The Dreyfus' take it to be an implication of their view that "an expert cannot improve future performance by abstract reflection on previous situations, actions and outcomes". ${ }^{17}$ The most important reason they give for this, for current purposes, is that detached reflection asks what it was about a previous action that made it satisfying or regrettable. This is like asking the competent chess player to figure out what principles of chess explain why a master made a particular move, or which neglected ethical principles explained why one felt regret in an ethical situation. But, they write, "as we have seen in the case of chess, in the next situation when one applies the principle one may well lose the game, or, in the case of ethical action, still feel regret. This is not because it is difficult to determine which features define membership in the right similarity set, nor because it is hard to find the principles which lead to expert action. Rather, as far as anyone knows, there just aren't any such features and principles". ${ }^{18}$

There is a possibly significant caveat to all of this dramatic particularism. The Dreyfus' concede that even experts might deliberate in some cases: "A chess master confronted with a chess problem, constructed precisely so as not to resemble a position that would show up in a normal game, is reduced to using analysis. Likewise an ethical expert when confronted with cases of "life-boat morality" may have to fall back on ethical principles". ${ }^{19}$ For my purposes it will do to draw attention to the way in which, even where a role for principles is acknowledged, it is only in novel or extreme cases, and, as the ranked or graded model implies, the Dreyfus' think such strategies inferior: the chess master is reduced to analysis, the ethical expert falls back to principles. Indeed the Dreyfus' continue explicitly: "But since principles were unable to produce expert behaviour for the competent performer, it should not be a surprise if falling back on them produces inferior responses. The resulting decisions are necessarily crude since they have not been refined by the experience of the results of a variety of intuitive responses to emotion laden situations and the learning that comes from satisfaction and regret." ${ }^{20}$

It seems to me this that is to get ethics quite wrong. One way to approach that conclusion is to draw attention to some disanalogies between driving and chess on the one

$17 \quad$ Above n 10, 245.

18 Above n 10, 246.

19 Above n 10, 248.

2) Above n 10, 243. 
hand and moral reasoning on the other. In driving and chess success does not depend upon being able to tell others why one has acted as one has. Putting aside problems of driving coordination, so concentrating on Dreyfus' own driving examples (such as successfully negotiating a curved motorway exit) success in driving - in the sense of simply successfully changing gears, negotiating corners and the like - does not require: that I can explain to others why I acted as I did; that others can accept that I have acted for the right motives; nor that they can engage in debate about what I have chosen to do and why. But that, I think, is precisely what ethics does require. The possibility of dialogue and discussion are non-optional components of adequate ethics. Without this possibility we are not engaged in ethics at all.

And now of course the claim is that an account which makes expertise at an endeavour amount to acting in a way which seems to defeat the point of the endeavour itself cannot be right. Note that this is an objection to the idea that on the Dreyfus' account the expert cannot make use of principles, cannot engage in dialogue in a way which would enable others to understand why she had chosen to act as she did. It is an objection to the idea that doing so involves taking a step back down the levels of expertise.

I do not think the acknowledgments toward the end of the account for some role for deliberation help: though I applaud the idea that one can't do ethics effectively "from the life-boat", I decry the suggestion that only in such cases can the giving of reasons have a proper place. In the end the idea is that ethics is an ineluctably and necessarily public activity in which the ability to explain one's reasons for action to others in not a mere and inferior "optional extra" to be tolerated in certain odd and rare cases. It is what the activity is about at its core, or when it is the full bloom of life, not merely at its periphery or in extremis. It cannot be right that in it's finest manifestation ethical reasoning renders ethical reasons opaque. ${ }^{21}$

\section{VIRTUE ETHICS AND LEGAL ETHICS}

I want now to refocus more directly on the application of virtue or character-based ethics to legal ethics. There are, I think, two sorts of reasons to be especially wary of the appeal to virtue ethics in this context. We can call them "macro" and "micro" ethical concerns. I will discuss each them in that order.

\section{A Macro-Ethical Challenges to Virtue Based Legal Ethics.}

I begin with an account of the nature and function of law. John Rawls has recently argued that the most significant question facing contemporary liberal communities is

${ }^{21}$ I give a positive account of the nature of moral expertise in T Dare "Challenges to Applied Ethics" Encyclopedia of Applied Ethics (SanDiego, Academic Press, 1997) 22-28. 
"[h]ow is it possible that there may exist over time a stable and just community of free and equal citizens profoundly divided by reasonable religious, philosophical and moral doctrine?"2 A central part of the liberal response to this question has been the establishment of procedures and institutions which aspire to an ideal of neutrality between the reasonable views represented in the communities to which they apply. The members of a pluralist community, the idea goes, will often be able to agree on the structure of neutral institutions and practices even where they cannot agree on the right outcome of a policy question as a substantive matter. Of course these institutions and practices cannot guarantee outcomes which will suit all the reasonable views: often there will be no such universally acceptable outcomes. The hope of liberalism, however, is that even those whose substantive preferences do not win the day on this or that occasion will have cause to accept the decisions of these institutions as fair and just. At the very least, they must have reason to believe that their views have been taken seriously and that the decision procedures have not simply turned the individual preferences of some members of the community into public policy to be imposed on all. Liberal community so understood is undercut by those who insist upon appeal to their own substantive views of the good rather than to the procedures. Appeals to individual judgment are likely to be conceptually confused as well: to suppose it legitimate to override public process when it conflicts with private judgment is to ignore the fact that it is the inappropriateness of appeal to private judgment which leads us to adopt public decision processes in the first place.

This discussion provides a response to Anthony Kronman. Kronman refers to his Arisotelian professional ideal as the "lawyer-statesman". As the epithet suggests, Kronman takes lawyers to have a significant leadership role. In the political sphere, the lawyerstatesman seeks a certain kind of political integrity, namely one which obtains despite the existence of significant and ineliminable conflict. The lawyer-statesman directs us to a condition of political wholeness in which "the members of a community are joined by bonds of sympathy, despite the differences of opinion that set them apart on questions concerning the ends, and hence the identity, of their community." ${ }^{23}$ By establishing bonds of fellow feeling among the members of a community, bonds based upon a willingness to sympathise with other's interests and concerns, political fraternity helps to counteract the destructive forces posed by groundless, yet identifying, choices which confront both individuals and communities.

2 J Rawls Political Liberalism (Columbia University Press, New York, 1993) xxv.

23 Above n 7, The Lost Lawyer, 93. It is significant that Kronman appeals to historical examples of the lawyer-statesman. He is led to "define" the phronimos ostensively, since he is suspicious of the possibility of doing so by appeal to anything like "principles" of deliberation or good character. The use of such principles would threaten to undercut the suppositions of the character approach. 
The discussion of the role of law and lawyers given above allows us a better account of these matters. First, note that the "procedural" story is directed precisely at securing political community in the face of ongoing substantive dispute. The neutral institutions of political liberalism aim to give us ways of going on as a community which take the reasonable views represented within our midst seriously, and which assure even those whose personal preferences have failed to carry the day that neither they nor their views have been ignored. Law is an essential part of the effort to secure stable and just political community between the advocates of diverse views of the good. Given this role, the procedural approach provides a response to Kronman's spiritual crisis as well: on the procedural account the various law jobs are extraordinarily important in pluralist communities and hence are ones in which lawyers can and should take pride.

One might think, indeed, that some such story would be a source of considerably more comfort to lawyers than Kronman's - it tells them, after all, that what most of them are doing has moral and political value. It seems not unlikely that any current crisis of morale would be made worse by Kronman's conclusion that contemporary lawyers belong to the generation which killed the lawyer-statesman. The lesson for legal ethics, I believe, is not that lawyers need to throw over the rule and principle based model of professional ethical obligation, but that they should be brought to appreciate the significance of the social roles they serve, and to understand and take pride in fulfilling the duties which flow from those roles.

We can usefully consider a recent discussion in light of this account of the role of law and its significance for legal ethics. David Luban appeals to an example in which an artist's cooperative had become a source of pride for the small town in which it is located. ${ }^{24}$ The cooperative was located in a building which was bought by an out-of-town developer. The legal profession in the town was divided between "old-timers" and "new-arrivals". The developer was represented by one of the latter, who did the legal work involved in raising the rent above the means of the cooperative, which eventually moved out and disbanded. The old-timers were apparently appalled by the conduct of the new-arrivals. They believed, we are told, that "real professionals" would have tempered the client's conduct for the good of the community. In a recent defence of a virtue based approach to legal ethics, Dean Cocking and Jusin Oakley write this about this case: ${ }^{25}$

24 D Luban in "Smith Against the Ethicists" (1990-1991) 9 Law and Philosophy 417-433, 427-430. Luban takes the case from a study of the legal community of a small New England town by Austin Sarat.

25 D Cocking and Justin Oakley "Doing Justice to the Lawyer's Role", Forthcoming in "Proceedings of the Australasian Association for Applied Ethics Annual Conference", Melbourne July 1997, p 6 of original manuscript. The Conference Proceedings will also include a fuller response to their paper by the current author: T Dare "Taking the Lawyer's Role Seriously: A Response to Cocking and Oakley". 
While the developer no doubt had a legitimate claim to develop their property, the lawyer's pursuit of this claim, uninhibited by its violation of other conflicting, commensurate legitimate claims, seems to fall short of, and unjustifiably claim a stance of immunity from, the claims of ordinary broad-based morality.

But a brief foray into "broad-based" moral and political theory, following the account given above, provides another perspective on the case. Suppose a community, not unlike our own, in which we find a range of views about property. Some people think that being a source of pride to your community gives you a property claim to the building in which you live or work. Others think that the owners of such buildings are those who have exchanged other property for them and who have had title transferred and registered in their names. The people of this community are likely to find themselves in communitythreatening disputes. We can imagine that they will see a need to decide which view of property, or more likely which compromise between these and other views represented within the community, is to recognised and protected.

Suppose that after careful debate and consideration of all the possible views they settle on something fairly close to the latter view. A system of property is instituted which allows those who have paid for buildings to insist upon transfer of title, and to deal with their buildings as a public system of property laws allows. This is not to say that owners under the system can do anything at all with their buildings. Some members of the community favoured such a system, but their preferences did not carry the day. Following the example of many other communities, for instance, this one recognises that tenants too have certain kinds of property rights, and it specifies, in particular that owners cannot evict tenants without giving specified periods of notice. Unfortunately, in the way of such things, the property-system of this community is such that most people require expert assistance to ensure that their rights under the system are protected.

This hypothetical allows us a number of points. It suggests that the property systems of such communities are ways of allowing community between people with different substantive views. On this view the role of the property experts in protecting the claims under the systems is a deeply important moral and political role. People who help others avail themselves of institutional rights need not apologise for what they do. Often their communities depend precisely upon the role they fulfil. Suppose some significant portion of the property system experts in a town advocated one of the views which was not preserved in the final public system of property laws, though it influenced the compromise. So confident are these experts of the correctness of their view that they are quite undeterred by the failure of that view to win fuller protection in the property system adopted by their community. They do various things to implement their own view ranging from counselling clients about the moral iniquity of the system to refusing to represent those who seek to avail themselves of their publicly allocated rights. 
Should we admire such experts? Surely not. Their conduct threatens to revive the very disputes which led to the public property system at the outset. It shows a spectacular moral arrogance, especially in a case such as Sarat's, where it is at least not obvious that the system of rights which allows the developer to evict the tenants is unreasonable. They seem to abuse their position as de facto gatekeepers to the enjoyment of publicly allocated rights. They impose a significant burden on people who need expert assistance, who must now run the risk of finding themselves represented by an expert who does not sympathise with the system or perhaps with its allocation of these rights to this claimant.

One of the striking things about the Sarat/Luban case, is that while one can see how the property system might have been different, the actual system does not seem to be patently morally unacceptable. Cocking and Oakley's sanguine acceptance that even in this fairly straightforward case, lawyers acting for the owner "violated ... other conflicting, commensurate legitimate claims" and "fell short of, and unjustifiably claim a stance of immunity from, the claims of ordinary broad-based morality" shows just how far one might be led astray by concentrating on one's own views of the moral good. To do so is to ignore the moral good of public institutions. Far from being troubled by the easy case, then, I think it allows us to see how the law functions, to appreciate the proper role of lawyers, and to see again, that the role-differentiated conception does not render the role of lawyers amoral let alone immoral. The case shows again why lawyers have moral grounds to take their roles seriously.

\section{B Micro-Ethical Challenges to Virtue Based Legal Ethics.}

The discussion in this section has so far focused upon what we might call "macronormative" concerns. I have suggested that the role of law in pluralist communities has significance for the ethical obligations of lawyers working within those communities. There are also "micro-normative" reasons to be wary of character-based approaches to legal ethics, reasons which focus not upon the political or social significance of law in general, but upon the nature of lawyer-client relationships.

Professional relationships are, I believe, marked by four distinctive features. First, client's dealings with professionals are typically about concerns of considerable importance to the client. The concerns and the importance may be of various kinds: Matters such as our own health, or the health of those we love, the safe birth of our children, the security of the goods we rely upon to provide for ourselves and our families, these are things which are important to us and they are the sorts of things that lead us to the offices of professionals. We do not tend to go to professionals for trivial matters.

Second, and familiarly, relationships between clients and professionals are typically marked by an inequality of expertise and hence of power. Professionals possess expertise, particular competence in an area, which clients require. This distribution of expertise lies 
behind the familiar idea that relationships between clients and professionals are fiduciary: relationships in which one side places trust in the other. The combination of these first two features importance and - specialist knowledge - creates a special relationship between professionals and their clients. The client must rely upon the professional for something of considerable significance which she, the client, cannot secure for herself. In effect, professionals control our access to things of great importance to us.

Third, clients are typically in a poor position to judge the expertise or diligence with which professionals perform their duties. If my lawyer tells me I am under a duty to pay some significant sum of money, or my doctor that I must have an particular operation, I must take their word that they have arrived at that conclusion only after the exercise of due professional care and expertise. I can of course go to another lawyer or another doctor, but I will suffer the same disability there. We can, I think usefully think of this as the "black box" analysis of client-professional relationships: the client delivers their problem into the hands of the professional. The professional works his or her magic upon it, and it emerges transformed from the black box. Although this is an extreme description, it captures, I think, the reality of client professional relationships for most clients.

Fourth, and finally, clients typically do not know their professionals "personally". Though there may have been a time when the local doctor was likely to be a friend as well, this is now increasingly unlikely. Many clients will know only those things about their professionals that they can glean in the space of a professional consultation and normally only those things which the professional chooses to reveal.

The result of these four characteristics of typical professional/client relationships is that the clients of professionals typically rely on relative strangers for something of significance in circumstances in which the client cannot assess the expertise or diligence with which their interests have been pursued. This characterisation of the client-professional relationship, I believe, has considerable significance for professional ethics.

We can approach the first implication by considering the conditions under which we would normally be prepared to take on the vulnerability which marks our position in professional relationships. We might think, 1 propose, that lay-people place themselves in positions of vulnerability in their relationships with professionals in a way and to an extent which they would typically reserve for much more intimate relationships such as those we enjoy with family or friends. In these latter relationships we have grounds - our intimate or personal knowledge of the individual - to make assessments of the character of the person to whom we are vulnerable, of their motivations, their priorities and so forth, which explain our willingness to place ourselves in their hands, at their disposal. The contrast is suggestive for professional ethics. One of the things clients require is some way to judge in the absence of more intimate access to the values of the professional just what values will figure, and how, in the professional's dealings with the client. 
The standard conception of the lawyers role - and its analogous conception in other professions - goes a good way to meeting this problem. In essence, it requires the professional to deal with the client, not upon the basis of the professionals own moral views - which are likely to be opaque to the client, but upon a set of public and roledifferentiated professional values. The features of professional relationships highlighted above contribute to the importance of role-differentiated professional obligation. It is impractical to expect clients to inquire into the ethics of individual professionals. They must, however, be able to make some judgment as to those ethics. Given the vulnerability of clients and the fact that much of the work of professionals is inevitably out of the control and observation of the client, it is important not only that professionals are ethical, but that clients and potential clients have some way of knowing the ethical stance of practitioners even though they do not know them or their personal moral views.

Here the idea of "not only must justice be done, but that it must be seen to be done" has practical import. The adoption and promulgation of a distinct professional morality is a way of publicising the ethical stance of the profession. The official ethics of the profession can be public in a way that the personal ethics of its members cannot. However, clients get the benefit of these "public ethics" only if they are indeed given priority over personal ethics in members' dealings with the public. The client need only know that the professional is acting in a professional role, and what values that role requires the professional to adopt, to know what values will govern the professional's conduct in the relationship.

My claim here is that the "character aspect" of the virtues story makes that story inappropriate for professional and legal ethics. Clients do not have access to the character of their professionals. What clients require is a public statement of the rules and principles that will guide the professional and that those rules and principles be taken seriously by professionals. All of this I think shows character or virtue based ethics to be inappropriate in professional contexts. Such ethics fail to address the problems of inequality of expertise, the importance of issues and the opacity of diligence which mark professional relationships. Bluntly, if clients do not know in advance when their lawyers will have a fit of courage and judge that this or that interest of the client should be sacrificed to the good of the law, then the moral demands produced by the peculiar features of the professional lay relationship will not be met.

It may be useful to take the analysis offered a little further. I have suggested that laypeople place themselves in positions of vulnerability in their relationships with professionals in a way and to an extent which they would typically reserve for much more intimate relationships such as those we enjoy with family or friends. We can, I think, usefully understand many of the ethical constraints upon professionals as aimed at reproducing, in professional relationships, the central features of those more intimate 
relationships in which the vulnerability of the client would more naturally be found. Although the client does leave herself in a peculiarly vulnerable position with respect to the professional, she should be able to rely upon the professional to act toward her as if she really were someone with whom she enjoyed the more natural intimate relationship of friendship: she should be able to be confident - and here we see how the story allows us to deduce and explain the detail of professional codes of ethics - that the professional will act in good faith, out of care for the client's interests and so on. ${ }^{26}$

\section{PROFESSIONAL ETHICS AND THE STANDARD CONCEPTION}

My principle concern thus far has been to suggest that we should be wary of virtue or character based ethics in general and of the application to legal ethics in particular. I want to finish by saying a little more about the positive moral attributes of the standard, roledifferentiated, conception of the lawyer's role.

Opponents of the standard conception often suggest that it gives no place to ethics at all. Cocking and Oakley, for instance, characterise their opponents by saying that "various writers have wanted to defend a conception of the lawyer's role where the lawyer's advocacy of her client's legal rights is not constrained by broad-based moral concerns with which this advocacy might conflict." ${ }^{\prime \prime}$ Later they portray their opponents as claiming that "standards of ordinary morality have no place in the evaluation of professional conduct". Gerald Postema raises a similar concern, albeit a little more subtly, when he suggests that role-differentiation might promote a kind of moral failure or insensitivity. He concludes a list of related objections to the standard conception by writing: ${ }^{29}$

... most importantly, when professional action is cut off from ordinary moral experience, the lawyer's sensitivity to the moral costs in both ordinary and extraordinary situations tends to atrophy. The [standard conception] permits, even requires, that the lawyer regard his professional activities and their consequences from the point of view of the uninvolved spectator.

I hope the discussion thus far will have shown that the standard conception does not exclude ordinary morality in the ways these passages suggest, or have the alienating effect feared by Postema.

26 This analysis may capture the compelling aspects of the idea that the professional is the client's "special purpose friend". See C Fried "The Lawyer as Friend: the Moral Foundations of the Lawyer-Client Relation" (1976) 85 Yale Law Journal 1060-1089.

2 Cocking and Oakley, Above $n$ 25, 1 .

28 Above $n$ 25, 24.

29 G Postema, Above n 1, 79-80. 
I said at the outset of this discussion that we could usefully regard the appeal of virtue ethics in legal ethics as an attempt to reconcile the demands of professional and personal morality. Cast in that language, I am suggesting that professionals should ground their behaviour in the "public" ethics of their profession. The sort of considerations offered in this paper are moral considerations. Those concerns for the vulnerability of clients and for the importance of the issues with which they come to professionals should raise moral concerns for professionals, and the nature of moral reasoning. We might conclude, then, that one of the demands of an adequate personal morality will be to take the demands of public role-differentiated professional morality seriously. The way to make good lawyers good people is, I think, not to dramatically change the conditions and presuppositions of professional practice, but to point out to practitioners that the standard conception makes legitimate moral demands upon them. Similarly, there is little reason to think the standard conception need have the effect Postema fears. Again, if lawyers can be made to appreciate that there are significant moral reasons to take their roles seriously, they need not ignore the moral costs of their professional conduct. It may be, of course, that this view of the importance of their role will lead them to different judgments than they would make were they to respond as non-role occupants. This is not to say, however, that they are morally insensitive. It may show instead that they have more accurately assessed the importance of their role and its place in the community. 